\title{
ESTUDOS
}

\section{Interseção cultura-educação: necessidade pedagógica}

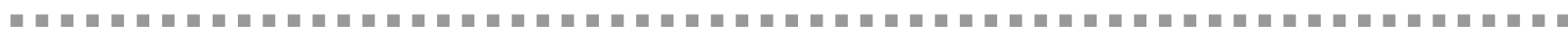
Maria José Lindgren

Alves

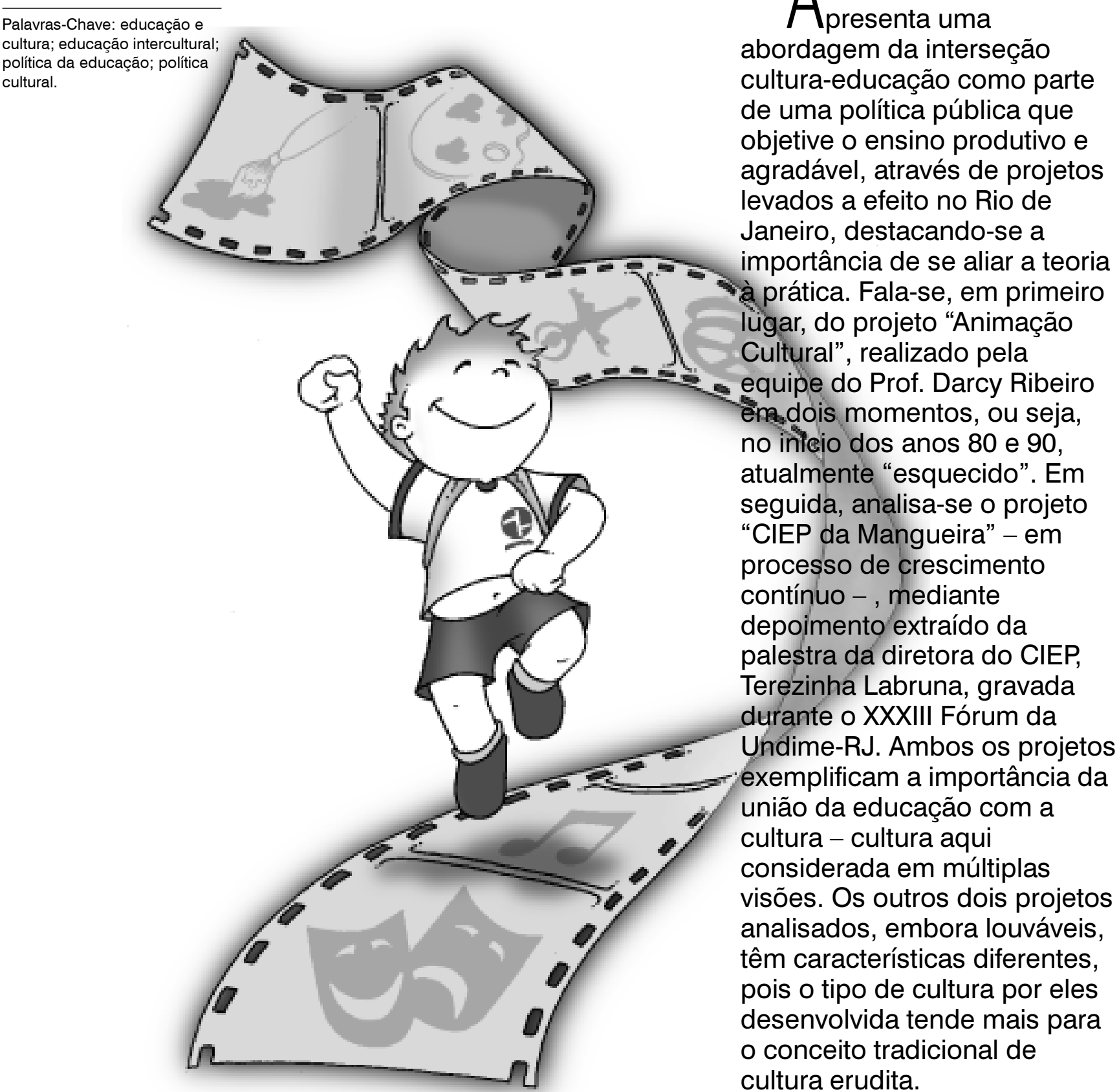




\section{Introdução}

Para desenvolver o tema da interseção cultura-educação, com enfoque em alguns projetos postos em prática no passado ou em curso no Estado do Rio de Janeiro, apresento, em primeiro lugar, uma seleção, ainda que modesta, do que alguns autores consideram como política pública, em geral, e políticas educacional e cultural, posicionando estas últimas, em relação ao problema específico brasileiro, sobretudo, dos anos 50 aos anos 80 . Esta última década é de particular interesse por demarcar a primeira fase do projeto que escolhi como prioritário para descrição e análise.

Em seguida, passo a focalizar o projeto propriamente dito, "Animação Cultural", recorrendo ao que sobre ele escreveram seus idealizadores e ao que eu própria pude testemunhar como co-partícipe de um exemplo bastante expressivo, segundo minha opinião, de política pública a um só tempo educacional e cultural interseção difícil e rara - idealizado por Darcy Ribeiro, elaborado e implementado por uma equipe de profissionais afinados com suas idéias, em dois momentos da política estadual e municipal do Rio de Janeiro, a saber, em 1984 e em 1991, com um intervalo de quatro anos, devido à descontinuidade quase sempre característica das políticas partidárias brasileiras. $\mathrm{O}$ projeto foi idealizado para escolas de horário integral - os Centros Integrados de Educação Pública (CIEPs), como exemplo a ser seguido em outras escolas.

O presente artigo estende-se a outras iniciativas em curso, agora, ao final dos anos 90, na Secretaria Municipal de Educação do Estado do Rio de Janeiro, que descreve brevemente, detendo-se, em especial, num trabalho que se efetiva em CIEP do estado - o "CIEP da Mangueira". São projetos distintos em suas características, sendo que o da Mangueira apresenta, em alguns aspectos, semelhanças com o projeto de "Animação Cultural". Alegam os implementadores dos projetos analisados buscar uma integração das duas áreas, a da cultura e a da educação (registro aqui a boa acolhida dos assessores de ambas as Secretarias).

Quanto à metodologia, foi utilizada a análise de documentos de circulação geral, porque publicados, ou de circulação limitada, por terem sido reproduzidos em xerox.
Cabe ressaltar o precioso depoimento da professora Terezinha Labruna, substituta do Subsecretário Adjunto de Cultura do Estado do Rio de Janeiro, o Sr. Francisco Carvalho, obtido por ocasião de mesa-redonda e debate do XXXIII Fórum da União dos Dirigentes Municipais de Educação (Undime-RJ), onde trabalho, do qual foram reproduzidos e comentados alguns trechos.

\section{Política pública - um assunto complexo e delicado}

Política pública não é um conceito de fácil definição. Subirats (1992) nos aponta uma série de definições do termo inglês "policy", chamando atenção para o caráter "notoriamente polissêmico" do termo política. Dentre as definições mencionadas, toma-se as seguintes, traduzindoas do texto em espanhol:

- "a política do governo sobre um tema como sinônimo de norma ou conjunto de normas que existem sobre determinada problemática" (idem, p. 40), aplicando-a ao tema da problemática da educação pública, com ênfase na educação escolar das camadas mais pobres da população;

- a política como "resultado (outcome), como impacto verdadeiro sobre a realidade". Neste ponto, relaciona-se o conceito com a implantação dos CIEPs, de atendimento praticamente voltado para as crianças e jovens das populações menos favorecidas, também como uma política social efetiva ou como "seqüência de feitos e decisões que implicam um certo avanço ou modificação da realidade."(idem, p. 40-41).

Segundo Saravia (1990), a política pública não pode ser considerada isoladamente, pois ela faz parte de um todo de políticas do governo e deve ter como finalidade contribuir para o bem-estar social. Esta visão torna-se um tanto utópica, se atentarmos para a história política e econômica de nosso país, sobretudo durante os regimes populistas e/ou autoritários que facilitaram a instalação e a irradiação do clientelismo, do favoritismo e do corporativismo de que nos fala Cunha (1995, p. 21), com conseqüências graves para o desequilíbrio e as desigualdades sociais.

É Saravia ainda que apresenta um conceito abrangente e válido de política pública: 
Trata-se de um sistema de decisões estimuladas por uma autoridade, que se traduzem em ações ou omissões, preventivas ou corretivas, destinadas a modificar ou manter a realidade de um ou vários setores da vida social, através da determinação de fins últimos, objetivos e estratégias de atuação (Saravia, 1991, p. 3).

\section{Política educacional/política cultural - separação ou união?}

Nosso atraso educacional é uma seqüela do escravismo. Nós fomos o último país do mundo a acabar com a escravidão. (...) O fracasso brasileiro na educação nossa incapacidade de criar uma boa escola pública generalizável a todos, funcionando com um mínimo de eficácia é paralelo à nossa incapacidade de organizar a economia para que todos trabalhem e comam (Ribeiro, 1986, p. 16).

Essas palavras de Darcy Ribeiro, coincidentes com as de Cunha (1995, p. 31), quando diz que "o escravagismo deixou marcas persistentes na escola atual", demonstram que falar de política educacional, no Brasil, significa enfatizar que as políticas educacionais tentadas ou implementadas pelos governos, de modo geral, não conseguiram abranger a todas as crianças, aos jovens e adultos das classes populares, marginalizando-os, com freqüência, do processo educacional, numa aflitiva situação de exclusão até hoje não resolvida.

Em relação a épocas mais recentes da história da educação brasileira - recorte que me parece necessário para o trabalho pretendido - verifica-se que a situação se agudiza sensivelmente com a migração interna de grandes contingentes da população do campo para as cidades, por falta de uma política de fixação do homem ao campo, que hoje, ao final dos anos 90, desencadeou o Movimento dos Sem-Terra, em prol de uma reforma agrária prometida, mas nunca efetivada.

Nos anos 80 , quando se inicia a redemocratização do país, segundo Cunha, (ibid., p. 32) mais da metade da população total concentrava-se em nove áreas metropolitanas no Brasil, criando problemas enormes para a administração de políticas públicas educacionais para todos. Nos anos 50 , a política edu- cacional para todos havia sido exercida pelo rádio e dos anos 60 em diante, passa a ser levada a efeito pela grande "educadora" de massas da modernidade - a televisão - que, nas mãos dos defensores do capitalismo e dos governos militares, causou franco prejuízo para a educação democrática, em geral, e para a educação escolar, em particular, que não tinha como competir com o irresistível apelo televisivo.

E o que dizer-se da política cultural? Como nos assegura Saravia, ela "é parte inseparável dos processos de dominação política" (Saravia, 1991, p. 2). Portanto, sem dúvida, favorecia as necessidades dos poderes populistas e/ou autoritários dominantes no país. A partir de 1964, intensificando-se em 1968, quando impera no país o regime militar, a censura política imposta aos meios de comunicação, educativos e culturais, a perseguição aos escritores, professores e artistas que não aceitavam as imposições e arbitrariedades da ditadura, ia conformando as mentes brasileiras menos esclarecidas ou mais interessadas em manter privilégios das classes dominantes às políticas de "Brasil Grande", "Pra Frente, Brasil" para uma minoria apenas.

Apesar de tudo, sentia-se a reação e o florescimento concomitantes de uma "contracultura" que, aqui e acolá, conseguia, muitas vezes valendo-se de subterfúgios metafóricos, extravasar suas idéias e colocar para o público suas produções artístico-culturais, sentidas principalmente na música popular e nas artes cênicas. $E$ as manifestações espontâneas do povo que seguiam seu caminho...

Ressalte-se a importância do trabalho renovador de Aloísio Magalhães, em 1979, que "incorporou à problemática da ação cultural questões fundamentais", como a preservação patrimonial e a participação da comunidade na tomada de decisões (Saravia, 1982, p. 11-12).

Com a eleição dos governadores, nos anos 80 , inicia-se um movimento de "abertura política" que iria influenciar decisivamente as políticas dos governos locais. É neste período de esperança e renovação que despontam programas e projetos inovadores em educação, particularmente em nível regional, nos governos estaduais e municipais. E é então que aparece o projeto da "Animação Cultural" dos CIEPs, no Estado do Rio de Janeiro. 


\section{"Animação Cultural” - um projeto pedagógico-cultural}

(...) a educação não pode mais ser dissociada das manifestações culturais e artísticas, sobretudo daquelas que já se desenvolvem no interior da própria comunidade (Ribeiro, 1986, p. 49).

Antes de abordar o projeto central deste trabalho, a saber, o projeto "Animação Cultural", importa ressaltar as concepções interculturais dos currículos do Programa Especial de Educação (PEE) I e II, que, já no início dos anos 80 , defendiam a necessidade de se articular, na escola, diferentes tipos de cultura, como a do professor (de classe média), a do alunado e de sua comunidade (majoritarimente de classe popular), respeitando-se os diferentes falares peculiares dos(as) alunos(as) e da comunidade, aproveitando-se o saber assistemático trazido para a escola, acrescentando-lhe outros conhecimentos, numa troca permanente, sem superioridades e preconceitos.

O Programa Especial de Educação dos CIEPs, dentro do qual se destacavam vários projetos inovadores, saído do ímpeto criador de Darcy Ribeiro, a esse tempo vice-governador e secretário de Cultura do Estado, construir-se-ia em torno do eixo pedagógico educação-saúde-cultura.

A saúde não será abordada com pormenores, neste trabalho, ainda que se deva mencionar sua concepção de promoção e prevenção de saúde, com envolvimento de todos os setores da escola, estendendo os dois aspectos às famílias e às comunidades, em conseqüência.

Apesar de o termo "educação intercultural" ser mais difundido atualmente na Europa, por conta dos imigrantes, dos ciganos e de outros, que forçaram a escola a considerar a pluralidade cultural, no Brasil, só agora começam a ser divulgados trabalhos sobre o assunto, não só acadêmicos, como oficiais (no caso, os novos Parâmetros Curriculares Nacionais, elaborados para o ensino fundamental em 1997, quando fala dos Temas Transversais), tomando diversas denominações, como educação multicultural, educação multi-étnica, anti-racista ou pluralista. Educação intercultural, segundo Jordan, se opõe ao conceito fácil de "integração" e não deve traduzir-se em assimilação de diferenças culturais, mas só pode acontecer, realmente, com uma "saudável integração sociocultural ou de um enriquecimento recíproco verdadeiro" (Jordan, 1996, p. 26).

Foi o que se pretendeu com o "Animação Cultural". Tomando de empréstimo os termos alemães "bildung" e "kultur", pode-se dizer que, naquele projeto objetivava-se a junção dos dois conceitos, o de cultura erudita e o conceito antropológico de "relações de sentido, explícitas e implícitas, concretizadas em modos de pensar, agir e sentir" (Sodré, 1983, p. 16). Portanto, conforme mencionado acima, o projeto visava a uma troca de valores culturais dos diversos grupos que atuavam nas escolas. O que interessava, em última análise, era romper com a barreira da exclusão encontrada na escola, a partir do comprometimento da educação com o resgate da cultura do povo.

A equipe central do projeto era constituída de pessoas do mundo da arte e da cultura, que procuravam trazer outras pessoas egressas do meio artístico: grupos teatrais, escritores e poetas, músicos, além de artistas destacados de movimentos espontâneos da comunidade: repentistas, sambistas, membros de bandas de música, escritores de cordel, Folia de Reis, etc. que, com a diversificação de linguagens, eram fundamentais ao processo de "entrada de mão dupla que favorece a erradicação de preconceitos e possibilita, a alunos e moradores locais, a identificação de valores regionais e universais do produto cultural que receberam" (Conde, 1995, p. 92).

Devido à seleção cuidadosa, só permaneciam elementos realmente engajados no processo. Trabalhavam em grupos de cinco elementos por escola, sendo a Fundação de Amparo à Pesquisa do Estado do Rio de Janeiro (Faperj) sua fonte de remuneração.

Os grupos freqüentavam reuniões sistemáticas com a equipe central e lhes era oferecido um treinamento, com pessoas conhecidas no campo das artes, como Amir Haddad, Augusto Boal, Rubem Gerschman, Yan Gherst, Tim Rescala, Caíque Botkai, Cecília Conde, Maria Lucia Freire e outros capazes de desenvolver temas e atividades, entre os quais, destacam-se: a proposta pedagógica do PEE como um todo; a questão específica da animação cultural na escola de tempo in- 


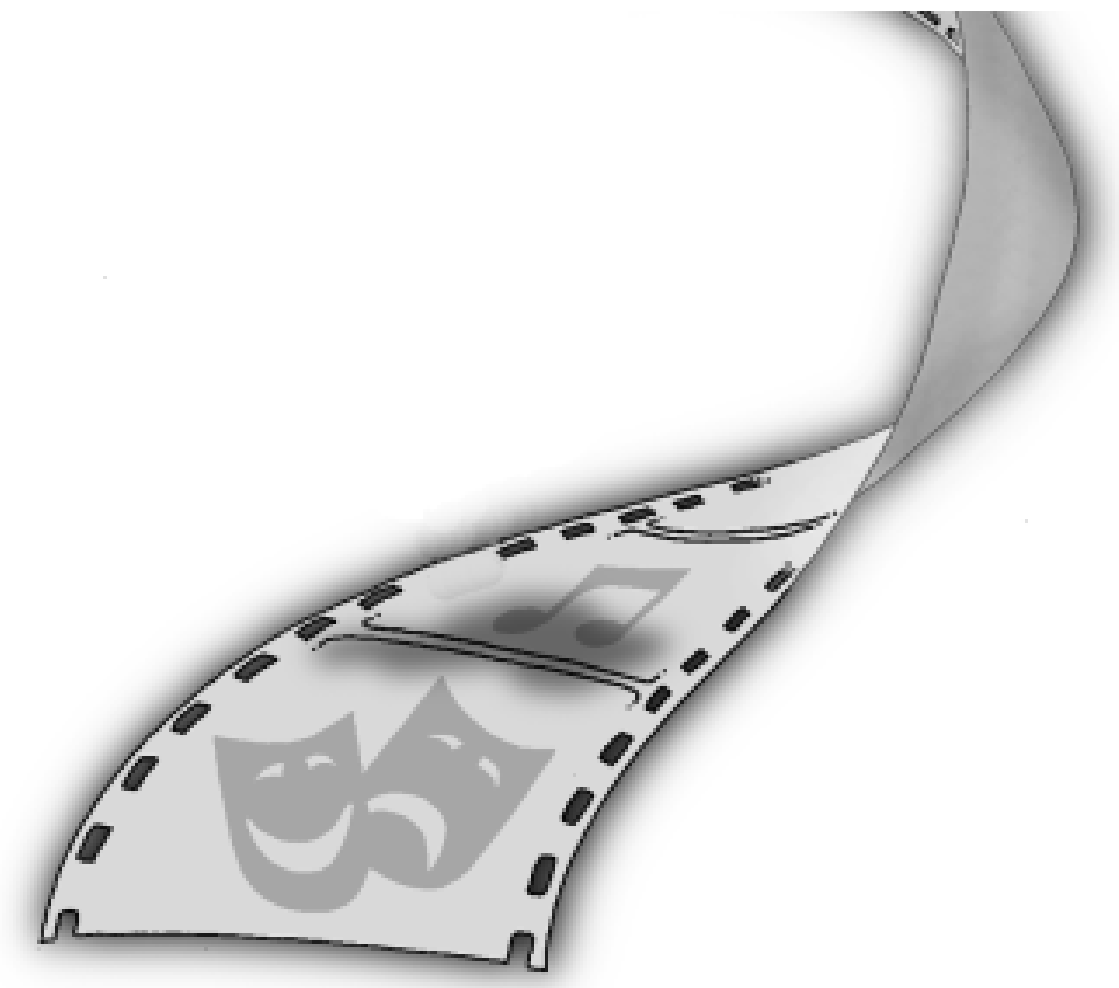

tegral; as diferentes linguagens da arte e dos meios de comunicação de massa.

$O$ treinamento era continuado e composto por módulos teórico e prático (no PEE II, principalmente). O módulo teórico incluía patrimônio arquitetônico da região; teatro na escola, relação corpo-espaçotempo, Teatro do Oprimido (incentivado por Augusto Boal, um dos pioneiros desse tipo de teatro participativo), elementos da cultura afro-brasileira, da arte e cultura da mídia, etc. O módulo prático tratava de técnicas para integração de grupo, oficinas variadas de expressão corporal, trabalhos com argila, origami, levantamento cultural da comunidade, música popular, etc. Os seminários finais de avaliação serviam para redirecionar as ações. Cumpre acrescentar que as capacitações envolviam também a direção das escolas e os(as) professores(as)-orientadores(as), ${ }^{1}$ sempre enfatizando a troca de experiências significativas na área, a cultura como fator de enriquecimento da ação pedagógica e como mediadora das relações entre o saber cultural da comunidade e o da norma "culta" da escola. (Conde, 1995, p. 95).

Para o artista não acostumado à formalidade da escola, foi possível engajarse no processo cotidiano da educação escolar, enquanto a escola foi-se acostumando com essa nova figura, às vezes bizarra até mesmo no trajar, aliando a pedagogia à cultura, o saber ao prazer, abandonando possíveis preconceitos.

Apesar das dificuldades encontradas, pode-se dizer que, no início dos anos 80 e com a sua retomada nos anos 90 , o pro- jeto foi atingindo seus objetivos. Em 1987, foi interrompido no estado, prosseguindo apenas no município. Foi retomado em 1991, no estado, mas, com a mudança de governo, em 1994, parou, mais uma vez. Atualmente, os animadores culturais perderam sua especificidade e estão lotados na Secretaria Municipal de Cultura, trabalhando em centros culturais, bibliotecas populares e comunidades (Dossiê sobre o "Animação Cultural" fornecido pela Secretaria de Estado de Educação do Rio de Janeiro,

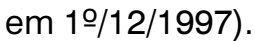

\section{Outros projetos em andamento}

\section{Projeto "CIEP da Mangueira" e outras iniciativas importantes}

Dentre os projetos atuais que visam à interseção educação e cultura, destaca-se, prioritariamente o Projeto "CIEP da Mangueira", desenvolvido pela Subsecretaria Estadual de Cultura na favela do Morro da Mangueira. Para analisar e descrever suas características, buscou-se subsídios no depoimento da professora Terezinha Labruna, que substituiu o Subsecretário Adjunto de Cultura, Sr. Francisco de Carvalho (o "Chiquinho da Mangueira"), reproduzido em gravação, durante mesa-redonda denominada "Integração Social da Escola", realizada no XXXII Fórum da União dos Secretários Municipais de Educação, na Undime-RJ, no município de Casimiro de Abreu, em outubro de 1997.

Segundo a professora, o projeto tem dez anos de existência e ganhou credibilidade especialmente pelo carinho que tem pelas crianças. No ano passado, recebeu o prêmio de melhor projeto social desenvolvido nos países do Terceiro Mundo, conferido pela Unesco, por indicação do ministro Edson Arantes do Nascimento, o "Pelé", ministro-secretário extraordinário do Desporto. Constitui-se de vários subprojetos: um projeto olímpico, desenvolvido na Vila Olímpica da Mangueira; um projeto educacional, o "GP 241 Nação Mangueirense",2 dirigido pela professora Terezinha Labruna; um projeto cultural, o "Mangueira do Amanhã"; um projeto desenvolvido no barracão sociocultural da Mangueira, dirigido a meninos de rua e a pessoas da terceira idade, e de um "Projeto de Solidariedade", implementado pela canto- 
ra Alcione, para dar atendimento e calor humano aos mendigos do centro da cidade do Rio de Janeiro. Ainda existe o projeto "Preparação para o Mercado de TrabaIho", que se desenvolve nos "campi" do Morro da Mangueira.

- Hoje em dia, temos a Golden Cross dentro da parte de saúde, o Banco Excel, a Xerox do Brasil e mais 168 empresas. Agora tornou-se mais fácil. Nós temos uma escola de qualidade, o "GP Nação Mangueirense", onde fazemos questão de manter aceso o sonho de Darcy Ribeiro, ou seja, ficar com o aluno na escola o maior tempo possível. (...) Um sonho que começou com Anísio Teixeira, mas Darcy era daqueles que seguiam com as idéias de alguém. $E$ a idéia de Darcy foi continuar o sonho de Anísio Teixeira. E surgiram os CIEPs.

Este ponto do depoimento deixa transparecer o esforço para conseguir parcerias empreendido pelos entusiasmados implementadores dos projetos mangueirenses, assim como deixa bem claro que a proposta pedagógica do "GP Nação Mangueirense" é semelhante à do CIEP, portanto, baseia-se em educaçãocultura-saúde, numa integração íntima e indispensável a uma escola de resultados efetivos.

- Os professores eram de 40 horas, com docência em matérias específicas... (...) não tinham um treinamento de uma preparação para trabalhar as atividades complementares. (...) Os professores das atividades complementares não tinham tido um treinamento ... Não Ihes faltava competência; faltava treinamento em habilidades específicas e nós tivemos um desperdício muito grande do horário integral porque o que estava havendo era uma repetição de aula. (...) Aproveitando a oportunidade de Diretora do Centro Cultural dessa agremiação, nós criamos o projeto "Artisticamente Mangueira". (...) Nós acreditamos que, através da arte, nós temos uma aliado forte contra a violência. Através da arte, podemos aproveitar aquelas manifestações culturais que a criança traz para a escola, porque ela não vem como um papel em branco, vem riquíssima de experiência e conteúdo. São 11 oficinas, sempre que ele (o aluno) tenha vontade de fazer.

Está aqui exemplificada a educação intercultural e a escola que aproveita o que a vida vai ensinando a seus alunos, além da intenção de prevenir a violência tão encontrada nas favelas e ruas do Rio de Ja- neiro. Em seguida, a professora fala da oficina "Dança de Rua", como "Street Dance", uma oficina que vem do baile funk e que porta este nome em inglês por marketing cultural, porque, segundo ela , fica mais "pomposo" do que simplesmente "Dança de Rua". Oferecem ainda oficinas de dança de salão, violão, guitarra, percussão, fabricação de instrumento com sucata e ginástica olímpica esportiva.

- (...) Então, nas oficinas de música, os alunos ensinam também os professores. Por exemplo, nós aprendemos com os alunos como é a batida da Mangueira, que é diferente de todas as outras escolas ( de samba): o surdão não tem resposta, o surdão bate, e a resposta é dada pelo repique. (...) Isso aconteceu, foi contado aos alunos através dos ensinamentos do mestre Valdomiro, que foi um dos principais mestres da bateria da escola.

Mais uma vez, o depoimento demonstra a troca, a não-superioridade de uma cultura sobre a outra, além de mostrar a importância da tradição cultural oral, transmitida pelos mais velhos às novas gerações, como acontece com muitas culturas, como as indígenas, por exemplo.

É mencionada ainda no depoimento a visita recente do presidente norte-americano Bill Clinton, preparada com esmero pelos mangueirenses e que merece louvor pelo esforço enorme despendido pela comunidade para conseguir melhorias, como computadores novos e mais modernos para a escola. ${ }^{3}$

\section{Programa "Horizontes Culturais"}

Não poderia deixar de falar do projeto enviado pela professora Lucia Lobo, assessora de gabinete da Secretaria Municipal de Cultura do Rio de Janeiro (SMC-RJ), após longa entrevista telefônica, uma vez que ficou flagrante a sua vontade de atender ao pedido de projetos que explicitassem a interseção cultura-educação.

O programa "Horizontes Culturais" é promovido pela SMC-RJ em parceria com a Secretaria de Educação, tendo iniciado em setembro de 1997. Destina-se aos professores da rede pública municipal com o objetivo de proporcionar-lhes condições de aprimoramento cultural, através da renovação constante do interesse pela vida cultural e artística e de uma formação cultural que permita o aproveitamento

\footnotetext{
${ }^{3}$ Por ter sido realizada durante palestra, a gravação do depoimento da professora Terezinha Labruna ficou um tanto prejudicada em algumas palavras. O conteúdo, porém, não sofreu nenhum tipo de deformação. A íntegra da gravação encontrase nos arquivos do escritório regional da Undime-RJ, na Universidade do Estado do Rio de Janeiro (UERJ), Bloco F, 9 ㅇ andar, NUSEG.
} 
prazeroso das manifestações artísticas, o desenvolvimento do gosto estético, valorizando as diferenças de temas, estilos e linguagens da produção artística contemporânea.

Está programado em duas fases, sendo a primeira, para os(as) professores(as), particularmente de Educação Artística, que se tornarão multiplicadores/as para as escolas, e a segunda, já estendendo aos estudantes do ensino municipal a política de formação de platéias. Durante a primeira, serão oferecidas oficinas dinâmicas de teatro e música, a freqüência dos professores a espetáculos de teatro, dança e concertos musicais, sem a pretensão de "formar artistas", mas "desenvolver o lado artístico de cada um" (Rio de Janeiro, s.d.).

As oficinas realizam-se em centros culturais da SMC, localizados em três regiões da cidade: Zona Oeste, Centro/Zona Norte e Zona Sul, e as programações dos espetáculos serão feitas nos teatros mantidos pela Prefeitura do Rio de Janeiro, desenvolvendo-se através de encenação teatral, jogos dramáticos, exercícios de sensibilização e concentração, aspectos constitutivos do teatro, arquitetura da arte cênica, noções de direção, cenários, iluminação e figurinos. Em música, prática vocal com exercícios técnicos e apreciação musical, com recursos de disc-laser ou vídeos. Os concertos e recitais serão basicamente de música erudita. Há também mostras de dança e espetáculos de poesia, patrocinados pela RioArte, ${ }^{4}$ sendo todas as atividades seguidas de discussões e debates com especialistas.

O documento chama a atenção para a importância da "bagagem cultural" dos que trabalham na escola para a ampliação e solidificação dos conhecimentos que ali se transmitem, o que torna mais rico e produtivo o ensino-aprendizagem, e para a preocupação de "fazer dos professores da rede municipal de ensino sujeitos da produção de suas próprias referências culturais e não objetos da transmissão de um saber qualquer" (Rio de Janeiro, 1997?).

Como se pode verificar, o programa "Horizontes Culturais" tem características diferentes dos projetos anteriormente descritos. Embora louvável como iniciativa cultural, dá ênfase ao aspecto da cultura erudita, sem preocupar-se muito com a cultura popular. Assim, não apresenta grande contribuição para a nossa escola, quase sempre tendente a valorizar os chamados "universais" da cultura ocidental, em detrimento da cultura popular, comumente vista como folclore, e não como facilitadora da construção dos conhecimentos dos estudantes das escolas públicas brasileiras, sobretudo na formação inicial das crianças.

\section{Projeto "A Cidade é Sua"}

Trata-se de um projeto cujo resumo foi enviado pela assessora da Secretaria Municipal de Educação, que se preocupa, também, com o tema da interseção cultura-educação, mas no sentido da preservação do patrimônio escolar, seu principal objetivo. Iniciou-se na Escola Deodoro, uma escola tombada do município do Rio de Janeiro, para um público-alvo de 30 professores.

Desenvolve-se através de palestras que abordam o acervo artístico e documental da escola; a arquitetura no contexto da cidade e a formação do cidadão dentro de tais perspectivas.

Tanto este projeto quanto o programa "Horizontes Culturais" enquadram-se perfeitamente na citação de Saravia (1982) sobre o conceito oficial de cultura no Brasil:

A noção de cultura que tradicionalmente norteou as políticas do governo brasileiro no terreno cultural manteve dois aspectos fundamentais e quase que exclusivos: a preservação do patrimônio histórico e artístico e o fomento às manifestações da cultura erudita, principalmente a música, a literatura e as artes plásticas (idem).

\section{Conclusão}

Após reflexão sobre políticas públicas, em especial sobre políticas educacional e cultural, para chegar ao tema da interseção cultura-educação, que tanto interesse nos despertou por considerarmos cultura como parte essencial da educação, conclui-se que um trabalho deste tipo enriquece ainda mais os ensinamentos anteriormente transmitidos, sobretudo em relação à educação intercultural, tão enfatizada, nos dias atuais, pelos elaboradores de currículos oficiais brasileiros, como uma grande e "nova" contribuição aos currículos escolares, mediante os Temas Transversais contidos no documento dos Parâmetros Curriculares para o ensino fundamental.

Reavivando a memória, mediante consulta a documentos publicados ou que re- 
latam iniciativas pedagógico-culturais que datam do início dos anos 80 , retomadas nos anos 90 e interrompidas em 1987 (graças à péssima tradição brasileira de interromper ações, sem que antes se proceda a uma avaliação justa e científica, junto a tentativas repetidas dos governos eleitos de sempre tentar inovações para marcar sua passagem), procurou-se, no presente texto, focalizar prioritariamente um dos projetos que nos parece mais ilustrativo da interseção cultura-educação: o "Animação Cultural".

O projeto é, na minha opinião de integrante atenta da educação fluminense, um marco de originalidade, uma espécie de feliz insight do antropólogo, escritor e professor Darcy Ribeiro e sua equipe, idealizado para as escolas de horário integral os CIEPs, mas que deveria ter sido estendido às demais escolas públicas do Estado e do município do Rio de Janeiro.

Além do "Animação Cultural", reporto-me a outro importante projeto em curso, o do "CIEP da Mangueira", que junto a um bom número de outros trabalhos vem tornando mais alegre, menos cruel e mais promissora a vida das crianças e jovens de uma das favelas mais conhecidas da cidade do Rio de Janeiro - a Mangueira, antes restrita quase exclusivamente à alegria do samba, da preparação e do desfile do Carnaval.

Outros dois tipos de interseção são brevemente abordados no texto presente: o programa "Horizontes Culturais"e o projeto "A Cidade é Sua", ambos da Prefeitura do Rio de Janeiro, cada qual com suas boas intenções de unir educação e cultura, porém com enfoques bastante diversos dos projetos prioritariamente descritos e analisados.

Espera-se, com este texto, ter contribuído, de algum modo, para que a memória das ações educativo-culturais de valor não se extinga, a fim de que se possa dar sempre um passo à frente, sem solução de continuidade, na interseção cultura-educação, de resultados efetivos para o crescimento do povo de nossa terra.

\section{Referências bibliográficas*}

CONDE, Cecília Fernandez et al. Animadores culturais. In: RIBEIRO, Darcy, NIEMEYER, Oscar, MEMÓRIA, Tatiana. Carta $n^{\circ} 15$, O novo livro dos CIEPs. Brasília : Centro Gráfico do Senado Federal, Gabinete do Senador Darcy Ribeiro, 1995. 297 p.

CUNHA, Luiz Antônio. Educação, Estado e Democracia no Brasil. São Paulo : Cortez; Niterói : EDUFF; Brasília : Flacso do Brasil, 1995. 495 p.

JORDAN, J. A. Propuestas de educación intercultural para profesores. Barcelona : CEAC, 1996. $173 \mathrm{p}$.

RIBEIRO, Darcy. A proposta pedagógica dos CIEPs. In: O LIVRO dos CIEPs. Rio de Janeiro : Bloch, 1986. $151 \mathrm{p}$.

RIO DE JANEIRO. Secretaria Municipal de Cultura. Dossiê sobre os animadores culturais. [s.d.]. xerox.

Projeto Horizontes Culturais. 1997?. xerox.

SARAVIA, Enrique. Perspectivas da cultura brasileira. Rio de Janeiro, 1982. xerox. . Política cultural na área de música. Bahia, 1990. xerox.

La elaboración de la política pública en el área de la cultura. Venezuela,

1991. xerox

SODRÉ, Muniz. A verdade seduzida : por um conceito de cultura no Brasil. Rio de Janeiro : Codecri, 1983. 215 p.

SUBIRATS, Joan. Análisis de políticas públicas y eficácia de la administración. Madrid: Ministerio para las Administraciones Públicas, 1992. 184 p.

\footnotetext{
* Os documentos da Secretaria Municipal de Cultura do Rio de Janeiro sobre os projetos em andamento na área da interseção cultura-educação, bem como o dossiê elaborado pela Secretaria Municipal de Educação do Estado do Rio de Janeiro sobre os animadores culturais não constam da bibliografia porque nos foram en viados por fax e por não terem sido publicados, segundo nos
} consta. 
Recebido em 4 de março de 1998.

Maria José Lindgren Alves é mestranda em Educação na Pontifícia Universidade Católica do Rio de Janeiro (PUC-RJ) e secretária executiva da União dos Dirigentes Municipais de Educação do Rio de Janeiro (Undime-RJ).

\section{Abstract}

The article intends to present a vision of the intersection culture-education as a part of a public policy which aims an efficient and pleasant teaching, through some projects put to practice in Rio de Janeiro, emphasizing the importance of joining theory and practice. First, we talk about the "Cultural Animation" project, developed by Prof. Darcy Ribeiro"s team in two moments, i.e., in the early 80 s and 90 s, which is presently "forgotten". Then, it is analysed the "CIEP da Mangueira" project - in process of continuous growth - , through the recorded words of the schoolmistress of the CIEP, Terezinha Labruna, during her lecture in the XXXIII Forum of Undime-RJ. Both projects exemplify the importance of joining culture and education - culture taken in its multiple visions. The two others, though praiseworthy, have different characteristics as to the type of culture aimed a more traditional concept of learned culture.

Key-Words: education and culture; intercultural education; policy of education; cultural policy. 